\title{
Study on the Current Status and System of Water Reuse Standardization in China
}

\author{
Zhang Xiaoxin ${ }^{1}$, Huang Jin ${ }^{1, *}$, Lin Ling ${ }^{1}$, Zhang Sinan ${ }^{1}$, Ding Qing ${ }^{1}$ \\ ${ }^{1}$ China National Institute of Standardization, Beijing 100191, China
}

\begin{abstract}
The paper examines the requirements of domestic policies and plans for water reuse standardization work, analyzes the current status and existing problems of domestic water reuse standards, builds China's water reuse standard system and conducts an in-depth study on the structure and composition of the standard system.
\end{abstract}

\section{Requirements of domestic policies and plans for water reuse standardization work}

The State Council issued the Action Plan for Prevention and Control of Water Pollution in April 2015, which mainly included performing an overall control of the pollutant emission, conducting the centralized treatment of water pollution in the industrial cluster areas, strengthening the treatment of domestic pollution in urban areas, and accelerating the construction and transformation of sewage treatment facilities in urban areas, and promoting the prevention and control of agricultural and rural pollution[1]. The State Council printed and issued the circular on the Comprehensive Work Plan for the Energy Conservation and Emission Reduction during the Thirteenth Five-Year Plan in December 2016, which mainly included strengthening the comprehensive treatment of domestic pollution sources, accelerating the construction and development of urban sewage treatment facilities and upgrading and transforming these facilities, improving the supportive pipelines, and enhancing the sewage collection and treatment capability. According to the Plan, it's imperative to design the reasonable sewage discharge system, strengthen the supervision and management of the system operation and guarantee that all the sewage treatment plants measure up to the sewage discharge standard, promote the use of reclaimed water, improve the facilities to use reclaimed water, stress the safe sludge treatment in sewage treatment plants, and prevent the secondary pollution. It's important to accelerate the construction of sewage collection pipeline, complete the construction and transformation projects of sewage, wastewater and sludge treatment facilities in the cities and industrial parks, advance the construction of reclaimed water reuse facilities, speed up the pollution control of large-scale livestock and poultry farms, and ensure the construction of solid wastes and wastewater storage and treatment facilities in over $75 \%$ farms. By
2020, all the counties and key towns shall have the sewage treatment capability and the cities at and above the prefecture level shall have the abilities to collect and treat all their wastewater. The cities and counties shall achieve the sewage treatment ratio of about $95 \%$ and $85 \%$ separately [2]. In December 2016, four national ministries and commissions including National Development and Reform Commission, Ministry of Science and Technology, Ministry of Industry and Information Technology, and Ministry of Ecology and Environment printed and issued the Development Plan for the Energy Conservation and Emission Reduction Industry during the Thirteenth Five-Year Plan in an aim to elevate the supply level of technologies and equipment for environmental protection, put more R\&D efforts into such key technologies as harmless and resource-oriented treatment of industrial sewage and sludge with high concentration and low degradability, promote the decentralized treatment of domestic wastewater in small towns and countryside and domestic and production wastewater in construction camps, and develop the policies and systems that contribute to the growth of energy conservation and environmental protection industry so that it becomes one of the pillar industries in China's national economy[3].

In conclusion, a lot of related policies, systems and plans from the end of the "Twelfth Five-year Plan" to the start of the "Thirteenth Five-year Plan" have been issued during the period from the end of the "Twelfth FiveYear Plan" to the start of the "Thirteenth Five-Year Plan". According to the requirements of these policies, systems and plans, the paper believes that some in-depth researches into China's water reuse standardization work should be conducted in the following aspects when the current status and existing problems of China's water reuse standardization work are taken into consideration.

1. The construction and improvement of water reuse standard system and standardization projects should be accelerated. Meanwhile, the standardization level of efficient water reuse should be systematically promoted

\footnotetext{
* Corresponding author: huangjin@enis.gov.cn
} 
and comprehensively elevated. The technical support of water reuse standard system and standardization system project in the national energy conservation and environmental protection industry should be fully exploited.

2. Strengthening the research and development of basic water reuse standards, performance testing methods and standards and evaluation management standards, and focusing the research and development work on high-performance evaluation standards, technical standards and procedures, and testing standards for products with proprietary intellectual property products, and standards for water reuse products and equipment.

3. The international standards or foreign advanced standards should be actively adopted, while encouraging a batch of national standards with proprietary intellectual property rights and core technologies to grow into international standards, enhancing the effectiveness and national influence of national technical standards for water reuse field, and breaking down the new trade barriers for green technologies as created in the water reuse field by the developed countries.

\section{Current status of domestic water reuse standards}

The municipal sewage treatment and reclamation facilities are the integral basic facilities in the city development and the important guarantee for economic development and people's safe and healthy lives. As of 2015 , the national municipal sewage treatment capacity reached 217 million $\mathrm{m} 3 /$ day, and the city sewage treatment rate was $92 \%$ and the country sewage treatment rate was $85 \%$. The construction of national municipal sewage treatment facilities has attained the goal as set in the "Twelfth Five-Year Plan". During the "Thirteenth Five-Year Plan", the state has made an overall plan and make more investments to ensure the transformation of city sewage treatment facilities from "scale-driven growth" to "improvement of quality and efficiency", from "more attention to wastewater than to sludge" to "equal stress on wastewater and sludge", and from "sewage treatment" to "reclamation" so that the guarantee and service performance of city sewage treatment facilities can be enhanced on a full scale[4-5].

However, there're still quite a few problems in our national water reuse field. First, China's most wastewater treatment and reuse techniques are featured by large energy consumption and large consumption of organic carbon sources. The consumption of energy and other resources can not merely increase the operation cost of water reuse system, but affect the sustainable use of limited resources and energy sources as well. Second, the water reuse process can generate many different types of secondary pollutants, including lots of residual sludge, screenings, stink, noise and various air pollutants as emitted by the production process. What's more, many domestic water reuse systems cause some major problems like poor water quality, high consumption of medicine and energy, high treatment costs, and much attention to construction and little attention to management in backward technique and equipment, less efficient management, workers' low operation level and low comprehensive utilization rate of resources. Now China's related water reuse standards are listed in Table 1.

Table 1 List of National Related Water Reuse Standards

\begin{tabular}{|c|c|c|c|}
\hline $\begin{array}{l}\text { Serial } \\
\text { No. }\end{array}$ & Code No. & Standard name & Issue departments \\
\hline \multicolumn{4}{|c|}{ Emission standards } \\
\hline 1 & $\begin{array}{l}\text { GB } \\
18918- \\
2002\end{array}$ & $\begin{array}{l}\text { Discharge Standard of } \\
\text { Pollutants for } \\
\text { Municipal Wastewater } \\
\text { Treatment Plant }\end{array}$ & $\begin{array}{l}\text { General } \\
\text { Administration of } \\
\text { Environmental } \\
\text { Protection }\end{array}$ \\
\hline 2 & $\begin{array}{l}\text { GB 8978- } \\
1996\end{array}$ & $\begin{array}{l}\text { Integrated Wastewater } \\
\text { Discharge Standard }\end{array}$ & $\begin{array}{l}\text { General } \\
\text { Administration of } \\
\text { Environmental } \\
\text { G...nt neral } \\
\text { General }\end{array}$ \\
\hline 3 & $\begin{array}{l}\mathrm{GB} / \mathrm{T} \\
31962- \\
2015\end{array}$ & $\begin{array}{l}\text { Wastewater Quality } \\
\text { Standard for Discharge } \\
\text { to Municipal Sewer }\end{array}$ & $\begin{array}{l}\text { Administration of } \\
\text { Quality Supervision, } \\
\text { Inspection and } \\
\text { Quarantine }\end{array}$ \\
\hline 4 & $\begin{array}{l}\mathrm{GB} / \mathrm{T} \\
24188- \\
2009\end{array}$ & $\begin{array}{l}\text { Quality of Sludge } \\
\text { from Municipal Waste } \\
\text { water Treatment Plant }\end{array}$ & $\begin{array}{l}\text { Ministry of Housing } \\
\text { and Urban-Rural } \\
\text { Development }\end{array}$ \\
\hline
\end{tabular}

Standard for Wastewater Reclamation

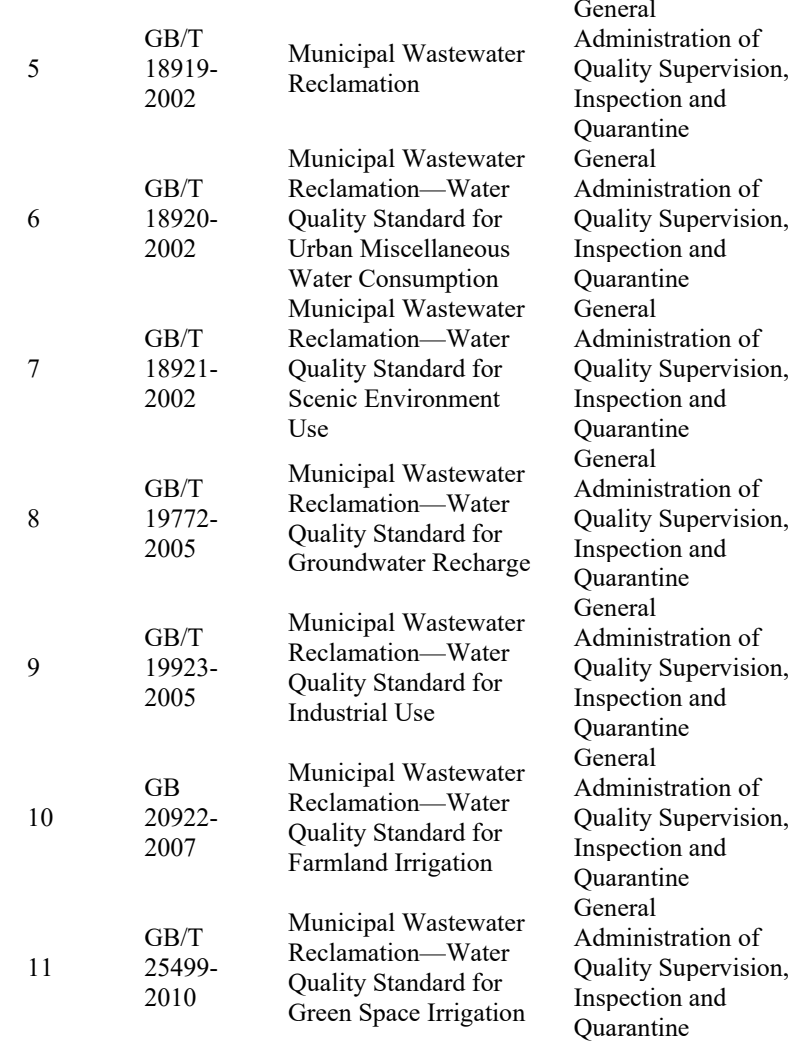

Technical specifications and standards for engineering 


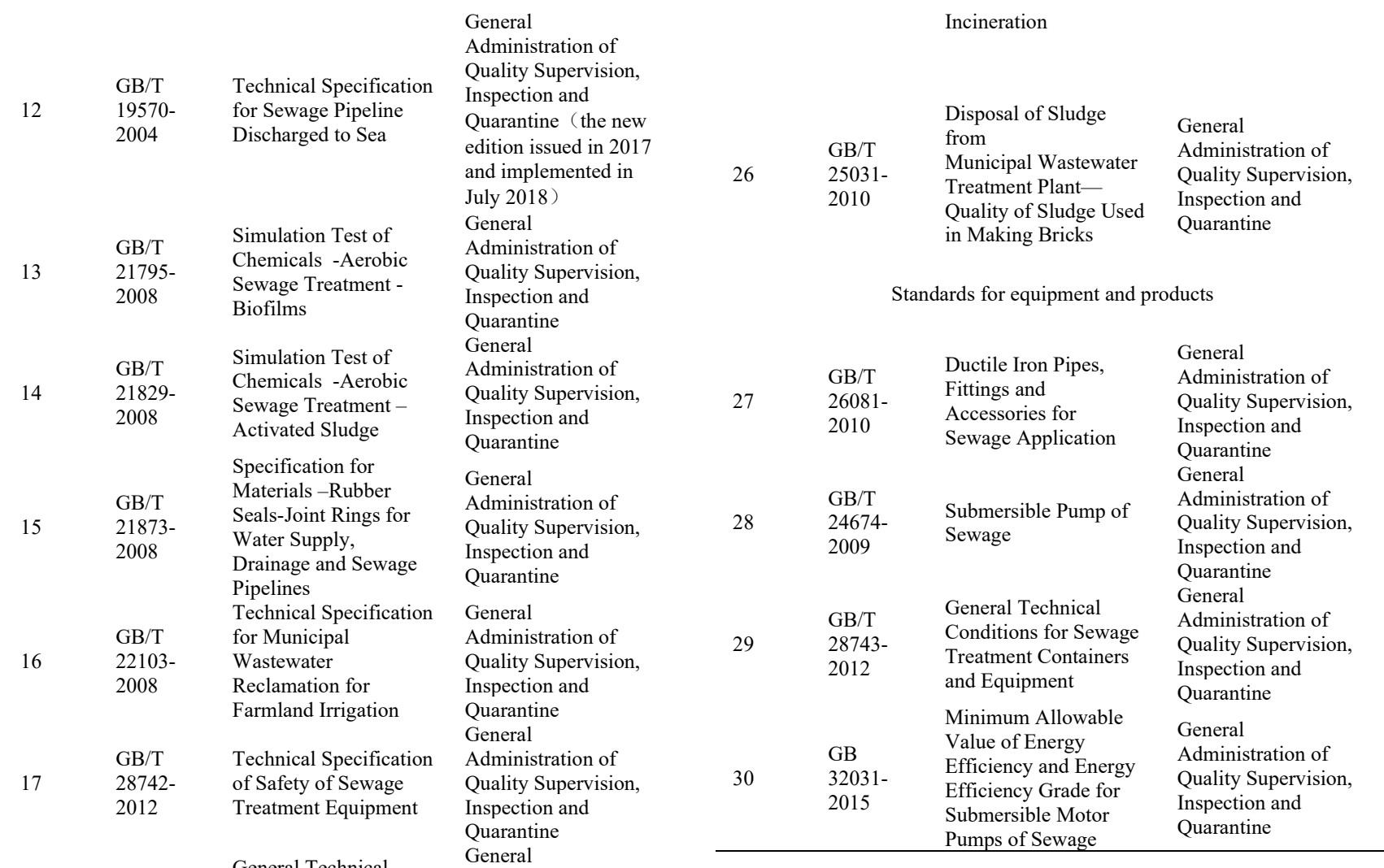

As Table 1 indicates, there are four emission standards among 30 national standards, including Discharge Standard of Pollutants for Municipal Wastewater Treatment Plant (GB 18918-2002), eight engineering technical specifications and standards, including Technical Specification of Safety of Sewage Treatment Equipment (GB/T 28742-2012), four standards for equipment and products, including Submersible Pump of Sewage (GB/T 24674-2009), seven standards for wastewater reclamation, including Municipal Wastewater Reclamation (GB/T 18919-2002), seven standards for disposal of sludge, including Disposal of Sludge from Municipal Wastewater Treatment Plant—Classification (GB/T 23484-2009). The distribution of standards by classification is indicated in Figure 1.

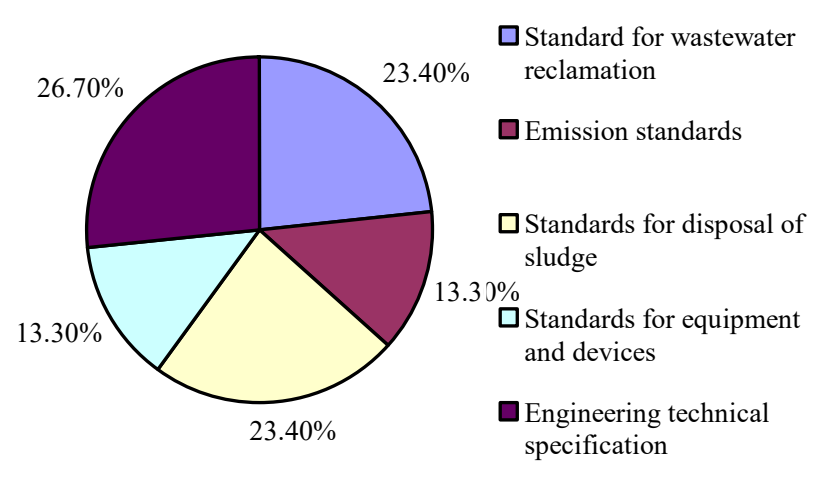

Fig. 1. Distribution of the related national water reuse standards by classification

In conclusion, China's water reuse system proves imperfect and lacks the support and guidance from the related policies, laws and regulations. The financial 
shortage restricts the development of water reuse work. The planning of municipal reclaimed water reuse starts later and is even absent. As far as standards are concerned, the discharge standards, engineering technical standards, standards for equipment and products, and standards for resources recycling are characterized by limited quantity and imbalanced distribution. There're no national monitoring and analysis standards and evaluation management rules. The scientific, complete, systematic, coordinate and operable features of the whole standard system need improving. The standards fail to play a sufficient role in regulating and guiding the development of industry, and the management mechanism of reclaimed water reuse is less well-established. Therefore, as the economic development and the awareness of energy conservation and environmental protection get stronger, it's an urgent need to build the standards and policies for water reuse and promote the growing maturity of water reuse treatment technique and technical roadmap.

\section{Construction of domestic water reuse standard system}

To address the need for China's socialism market economy and construction of water reuse market, perform the macro-control over the composition of water reuse standards and lay a foundation for the planning and annual plans of water reuse standards, China should build the scientific and reasonable water reuse standard system that has the coordinated relationship with production and development of water reuse in the shortest time possible, so that the water reuse standards can reap satisfactory standardization effects and the national water reuse standard system framework is created. The list of national water reuse standard systems is composed of general list and secondary systems or sub-systems. The general table falls into three vertical levels which can be horizontally subdivided into several types. Refer to Figure 2 for details.

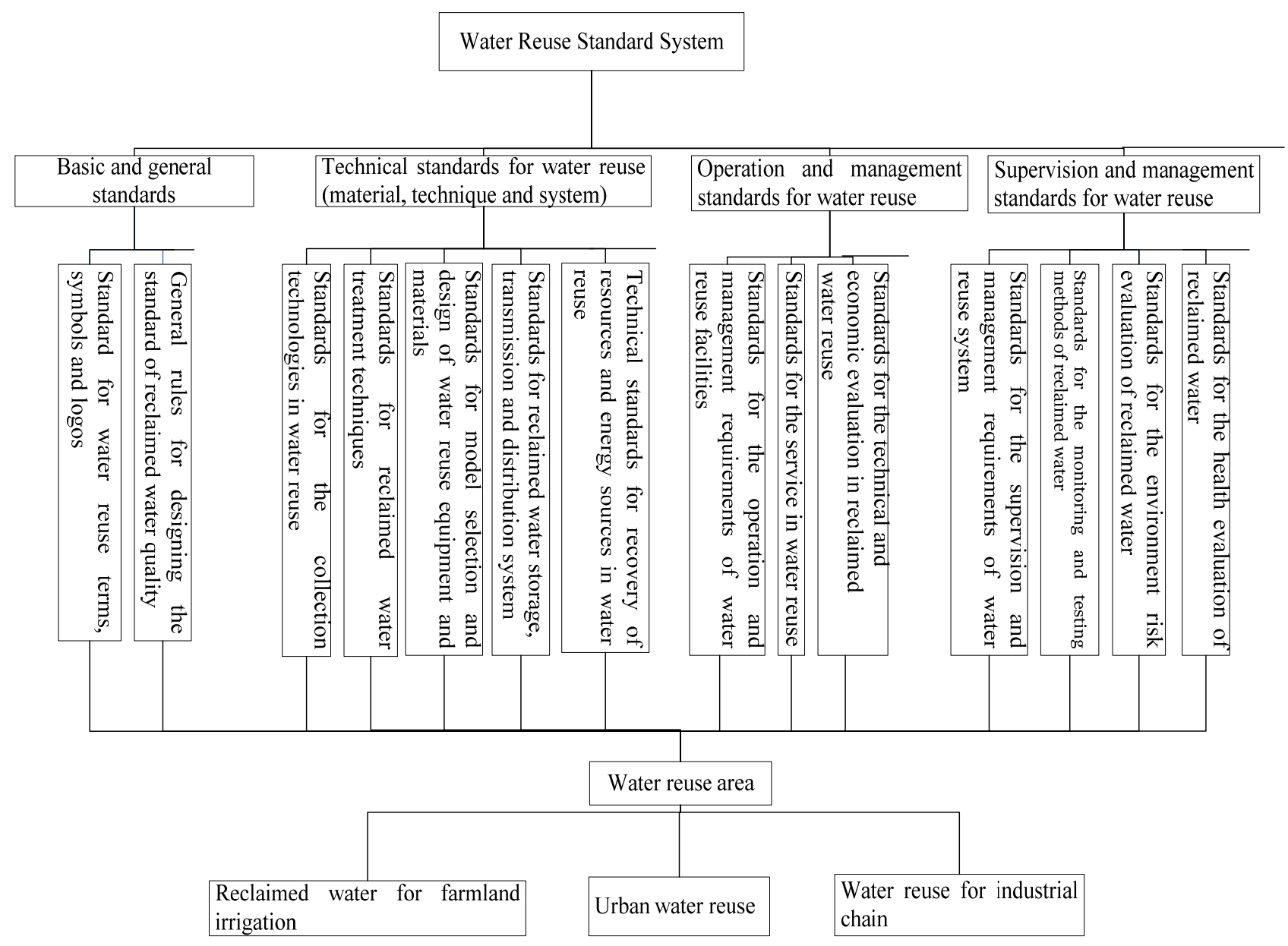

Fig.2 Framework of water reuse standard system in China

The first level is the secondary standard system, which can classify water reuse standards into four subsystems including basic and general standards, technical standards for water reuse (material, technique and system), operation and management standards for water reuse, and supervision and management standards 
for water reuse. The second level is the standards in four areas, which is the refined edition of the secondary standard system. All the standard sub-systems can be divided into reclaimed water reuse for irrigation, municipal water reuse and industrial water reuse if the form of water reuse is taken into account.

The basic and general standard subsystem starts with the overall consideration of water reuse, and creates a separate category out of the instructive basic and general standards in all the water reuse-related fields. This subsystem mainly includes standard for water reuse terms, symbols and logos, general rules for reclaimed water quality. Technical standard subsystem for water reuse (material, technique and system) is the technique and product standards necessary for $\mathrm{R} \& \mathrm{D}$, production and quality certification of equipment and products with water reuse technologies. This subsystem mainly includes standards for the collection technologies in water reuse, standards for reclaimed water treatment techniques, standards for model selection and design of water reuse equipment and materials, standards for reclaimed water storage, transmission and distribution system, and technical standards for recovery of resources and energy sources in water reuse. Operation and management standard subsystem for water reuse mainly includes standards for the operation and management requirements of water reuse facilities, standards for the service in water reuse, and standards for the technical and economic evaluation in reclaimed water reuse. Supervision and management standard subsystem for water reuse mainly includes standards for the supervision and management requirements of water reuse system, standards for the monitoring and testing methods of reclaimed water, standards for the environment risk evaluation of reclaimed water, and standards for the health evaluation of reclaimed water.

\section{Conclusion}

1. Currently, China's water reuse system proves imperfect. The discharge standards, engineering technical standards, standards for equipment and products, and standards for resources recycling are characterized by limited quantity and imbalanced distribution. There're no national monitoring and analysis standards and evaluation management rules. The scientific, complete, systematic, coordinate and operable features of the whole standard system need improving.

2. It's an urgent need to build the standard system for water reuse according to the related policies, systems and plans which are issued,. The list of national water reuse standard systems is composed of general list and sub-systems. If the type of standards is examined, the water reuse standards can be divided into four subsystems in 14 areas, including basic and general standards, technical standards for water reuse (material, technique and system), operation and management standards for water reuse, and supervision and management standards for water reuse.
3. It's necessary to further strengthen the research and development of basic water reuse standards, performance testing methods and standards, and evaluation management standards, and focus the research and development work on high-performance evaluation standards, technical standards and procedures, and testing standards for products with proprietary intellectual property products, and standards for water reuse products and equipment.

\section{Acknowledgement}

This work was supported by the National Key R\&D Program of China (2018YFF0213200) .

\section{References}

1. Action Plan for Prevention and Control of Water Pollution, (2015).

2. Comprehensive Work Plan for the Energy Conservation and Emission Reduction during the Thirteenth Five-Year Plan, (2016)

3. Development Plan for the Energy Conservation and Emission Reduction Industry during the Thirteenth Five-Year Plan, (2016).

4. S Gen-xing, D Qian, Y Fan, G Jinxin, Z Bolang, L Jianping. J. Shanxi Uni. Sci. Tech, 2014(3).

5. Z Xiaoxin, H Jin, L Lin, L Shuming. W Yueping, Z Xinheng. 2019 IOP Conf. Ser.: Earth Environ. Sci. 267 (2019). 